Review

\title{
Mechanism of Action of IL-7 and Its Potential Applications and Limitations in Cancer Immunotherapy
}

\author{
Jianbao Gao ${ }^{1}$, Lintao Zhao ${ }^{1}$, Yisong Y. Wan ${ }^{2, *}$ and Bo Zhu ${ }^{1,3, *}$ \\ 1 Institute of Cancer, Xinqiao Hospital, Third Military Medical University, \\ Chongqing 400037, China; E-Mails: nwgjb@163.com (J.G.); chaoren72@126.com (L.Z.) \\ 2 Lineberger Comprehensive Cancer Center, University of North Carolina at Chapel Hill, \\ Chapel Hill, NC 27599, USA \\ 3 Biomedical Analysis Center, Third Military Medical University, Chongqing 400038, China \\ * Authors to whom correspondence should be addressed; \\ E-Mails: wany@email.unc.edu (Y.Y.W.); b.davis.zhu@gmail.com (B.Z.); \\ Tel./Fax: +1-919-966-9728 (Y.Y.W); +86-23-6875-5626 (B.Z.).
}

Academic Editor: Kamal D. Moudgil

Received: 12 March 2015 / Accepted: 29 April 2015 / Published: 6 May 2015

\begin{abstract}
Interleukin-7 (IL-7) is a non-hematopoietic cell-derived cytokine with a central role in the adaptive immune system. It promotes lymphocyte development in the thymus and maintains survival of naive and memory $\mathrm{T}$ cell homeostasis in the periphery. Moreover, it is important for the organogenesis of lymph nodes ( $\mathrm{LN})$ and for the maintenance of activated $T$ cells recruited into the secondary lymphoid organs (SLOs). The immune capacity of cancer patients is suppressed that is characterized by lower $\mathrm{T}$ cell counts, less effector immune cells infiltration, higher levels of exhausted effector cells and higher levels of immunosuppressive cytokines, such as transforming growth factor $\beta$ (TGF- $\beta$ ). Recombinant human IL-7 (rhIL-7) is an ideal solution for the immune reconstitution of lymphopenia patients by promoting peripheral $\mathrm{T}$ cell expansion. Furthermore, it can antagonize the immunosuppressive network. In animal models, IL-7 has been proven to prolong the survival of tumor-bearing hosts. In this review, we will focus on the mechanism of action and applications of IL-7 in cancer immunotherapy and the potential restrictions for its usage.
\end{abstract}

Keywords: IL-7; cancer; immunotherapy 


\section{Introduction}

Interleukin-7 (IL-7) is a cytokine essential for the adaptive immune system. T lymphopoiesis in the thymus has been shown to be highly IL-7 dependent in mice [1]. In addition, IL-7 is important for T cell homeostasis and lymphopenia-driven proliferation [2]. It regulates lymph nodes (LN) organogenesis by controlling the pool of lymphoid tissue inducer (LTi) cells. By activating several intracellular signal pathways, IL-7 promotes the cell survival and proliferation of both naïve and memory $\mathrm{T}$ cells [3]. For its function on the maintenance of the naïve $\mathrm{T}$ cell pool and the survival of memory $\mathrm{T}$ cells, several clinical trials have been designed to use IL-7 to enhance immunity to viral infections and have achieved some success.

Cancer is a common disease worldwide and causes thousands of deaths annually. One important reason for tumor progression lies in that tumors can suppress the normal immunological surveillance function of the immune system of the organism to avoid detection [4]. Cancer patients often have an immunosuppressive status with lower $\mathrm{T}$ cell counts. In the tumor microenvironment, less infiltrated effector immune cells are predominantly composed of exhausted cytotoxic T lymphocytes (CTLs), T helper cell type2 (Th2) and macrophages (M2), which are tolerant toward tumors. There are also more $\mathrm{T}$ regulatory cells (Treg) and myeloid-derived suppression cells (MDCS) to inhibit effector immune responses.

In addition to killing cancer cells by chemotherapy and radiotherapy, immunotherapy has emerged as an attractive area of interest in recent years, which utilizes the immune system of patients themselves. IL-7 is an ideal target used to enhance the function of the immune system. It can reconstitute the immune system [5,6], improve $\mathrm{T}$ cell function in vivo and antagonize the immunosuppressive network. Thus, we focused on the application of IL-7 as an immunotherapy for cancer treatment and the action mechanism of IL-7. We also discuss limitations for the use of IL-7.

\section{Biology of IL-7 and Its Signaling}

IL-7 is mainly produced by non-hematopoietic cells including keratinocytes in the skin, fibroblastic stromal cells in the bone marrow [7] and lymphoid organs [8,9], epithelial cells in the thymus [7], prostatic epithelium [10] and the intestine. Immune cells, such as dendritic cells (DCs) can also produce IL-7 [11]. Moreover, IL-7 transcripts and proteins have also been found in normal adult human hepatic tissue produced by cells of lymphoid morphology [12,13]. The human IL-7 gene locus is $72 \mathrm{~kb}$ in length, resides on chromosome 8q12-13 and encodes for a protein of 177 amino acids with a molecular weight of $20 \mathrm{kDa}$. While the murine IL-7 gene is $41 \mathrm{~kb}$ in length, it encodes a 154 amino acids protein with a molecular weight of $18 \mathrm{kDa}$ [14].

The receptor of IL-7 is a heterodimer that consists of two chains: IL-7R $\alpha$ (CD127), which is shared with thymic stromal lymphopoietin (TSLP), and the common $\gamma$ chain (CD132) for IL-2, IL-4, IL-9, IL-15 and IL-21. The $\gamma$ chain is expressed on all hematopoietic cell types, while IL-7R $\alpha$ is mainly expressed by lymphocytes, including common T/B lymphoid precursors, developing $\mathrm{T}$ and $\mathrm{B}$ cells, naïve $\mathrm{T}$ cells and memory $\mathrm{T}$ cells [14]. Innate lymphoid cells (ILCs) are critical in lymphoid organ development and innate immune responses to pathogens. IL-7R $\alpha$ is also found in ILCs, such as NK cells and gut-associated lymphoid tissue (GALT)-derived LTi cells. IL-7 can also regulate lymphoid 
organogenesis by controlling the pool of LTi cells [15]. IL-7R $\alpha$ is regulated by stimulative transcription factors, GABP $\alpha$ and Foxo1 as well as inhibitory Gfi-1 [16-19]. TGF- $\beta$ promotes IL-7R $\alpha$ expression via the inhibition of Gfi-1 expression [20]. There is another type of IL-7 receptor: soluble IL-7R, which competes with cell-associated IL-7R to reduce excessive IL-7 consumption by IL-7R expressing target cells and enhances the bioactivity of IL-7 when the cytokine is limited [21].

There are two main signaling pathways responsible for the function of IL-7: Jak-Stat and PI3K-Akt [3]. IL-7R $\alpha$ is associated with the protein tyrosine kinase Janus kinase 1 (Jak1), and the cytosolic tail of the $\gamma$ chain is associated with Jak3. Binding of IL-7 to its receptor causes activation of Jaks in the cytosol, phosphorylating signal transducer and activator of transcription (STAT) proteins. The dimeric phosphorylated STAT (pSTAT) proteins subsequently translocate into the nucleus to activate gene expression. Via the Jak3-Stat5 pathway, IL-7 activates the anti-apoptotic genes, Bcl-2 and Mcl-1, and suppresses pro-apoptotic proteins, such as Bax and Bak. Consequently, naïve and memory $\mathrm{T}$ cells survive. This function is dose-dependent, such that a higher concentration of IL-7 induces thymic emigrant $\mathrm{T}$ cell proliferation, while lower concentrations sustain cell survival [22]. By activating the PI3K-Akt pathway, IL-7 downregulates the cell cycle inhibitor p2 $7^{\mathrm{kip} 1}$ to induce the expression of cyclin D1 for cell cycle progression [23]. Moreover, it promotes glucose transporter 1 expression, glucose uptake and mitochondrial integrity to positively regulate cell metabolism and size [14,24].

\section{Function of IL-7 in T Cell-Mediated Immune Response and the Underlying Mechanisms}

The immune system protecting the organism from cancer relies on the size of its $\mathrm{T}$ lymphocyte pool, especially the $\mathrm{CD}^{+} \mathrm{T}$ cell pool. This pool is maintained in a dynamic balance. Antigen-specific effector $\mathrm{T}$ cells fulfill their mission and subsequently die. Then expansion of new $\mathrm{T}$ cells supplements this pool. IL-7 retains this balance in three ways: thymopoiesis, homeostasis proliferation and life-support.

\subsection{IL-7 Signaling Is Essential for Thymopoiesis}

$\mathrm{T}$ lymphocytes are mainly generated in the thymus where IL-7 is necessary for their development. Mice deficient in IL-7 ${ }^{-/-}$, IL-7 $\mathrm{R}^{-/-}, \gamma \mathrm{c}^{-/-}$or Jak3 ${ }^{-/-}$suffer from severe lymphopenia, particularly for $\mathrm{T}$ and NK cells. A human mutation in IL-7R $\alpha$ results in a syndrome of severe combined immunodeficiency (SCID) with an absence of T cells [1]. During lymphoid cell development, the expression of IL-7R $\alpha$ is tightly controlled [5]. The development of $\alpha \beta \mathrm{T}$-cells in the thymus includes several stages, i.e., double-negative (DN) stages (DN1-4), immature single positive (ISP), double-positive (DP) and single positive (SP) $\mathrm{CD}^{+}$or $\mathrm{CD}^{+} \mathrm{T}$ cells. Early thymocyte progenitors do not express IL-7R $\alpha$. As $\mathrm{T}$ cell lymphopoiesis progresses, DN2 progenitors have the highest IL-7R $\alpha$ expression while DN4 cells express the lowest levels of IL-7 $\alpha$. IL-7 activates the transcription factor NFATc1 in DN thymocytes by phosphorylating Tyr371 in the regulatory region of NFATc1, a pathway that is critical for the survival and development of DN thymocytes [25]. Furthermore, DP cells lose their expression of IL-7R $\alpha$, but SP cells re-express it where IL-7 signaling promotes their survival and proliferation [26]. IL-7 signaling is also important for $\gamma \delta$ T-cells in inducing $\gamma$-chain rearrangement by enhancing histone acetylation and locus accessibility [27]. 


\subsection{IL-7 for Peripheral Homeostasis of T Cells}

IL-7 plays a critical role in peripheral T cell homeostasis [2]. There are very limited amounts of IL-7 under physiological conditions in vivo. Stromal cells produce IL-7 at relatively constant amounts and independently of external stimuli. Regulation of the function of IL-7 relies on IL-7R $\alpha$ levels [26]. In addition, binding of IL-7 downregulates IL-7R $\alpha$ expression by decreasing its gene transcription [19]. IL-7R $\alpha$ is highly expressed on naive and central memory $T$ cells. Once primed by the antigen, naïve $T$ cells differentiate into effector $\mathrm{T}$ cells and lose IL-7R $\alpha$ expression in an altruistic manner such that more naïve T cells obtain limited IL-7 to survive and proliferate. Nevertheless, IL-7R $\alpha$ is re-expressed when effector $\mathrm{T}$ cells differentiate to the memory stage.

In human lymphopenia diseases, such as HIV infection, idiopathic $\mathrm{CD}^{+} \mathrm{T}$ lymphopenia, high dose chemotherapy and auto-immune diseases, patients often have increased circulating levels of IL-7 and a strong inverse correlation between the levels of IL-7 and the number of CD4 ${ }^{+} \mathrm{T}$ cells. Higher levels of IL-7 induce $\mathrm{T}$ cell homeostasis proliferation outside of the thymus. After the recovery of $\mathrm{CD}^{+} \mathrm{T}$ cell populations, IL-7 returns to homeostatic levels due to naive CD4 ${ }^{+} \mathrm{T}$ cells expression of IL-7R, which consumes IL-7 to maintain their survival [28]. In lymphopenic mice, homeostatic $\mathrm{T}$ cell proliferation requires the transduction of signals from $\mathrm{T}$ cell antigen receptor (TCR) interactions with self-MHC class II and class I ligands, as well as with IL-7R [29]. However, IL-7 has more potent effects on $\mathrm{CD}^{+} \mathrm{T}$ cells compared with $\mathrm{CD}^{+} \mathrm{T}$ cells. In addition, $\mathrm{CD} 8^{+} \mathrm{T}$ cells survive better and proliferate faster than $\mathrm{CD}^{+} \mathrm{T}$ cells. Furthermore, IL-7 signaling on IL-7 $\mathrm{R}^{+} \mathrm{DCs}$ downregulates the expression of MHC class II on DCs, which is critical for the expansion of CD4 ${ }^{+} \mathrm{T}$ cells [11]. During $\mathrm{CD}^{+} \mathrm{T}$ cell homeostasis, IL-7 signaling must be intermittent due to continuous IL-7 signaling results in increased pSTAT5, which can activate IFN- $\gamma$ gene expression [30] and cell apoptosis triggered by IFN- $\gamma$ [31]. The intermittent interruption of IL-7R signaling is induced by TCR stimulation, which is dependent on the calcium-sensitive protease calpain to cleave the cytosolic tail of the $\gamma$ chain and dissociate Jak3 from IL-7R [32]. The TCR signal also acutely reduces Jak1 protein levels and prevents its synthesis to impair IL-7 signaling via microRNA-17 [33].

\subsection{IL-7 in SLOs Is Important for Adaptive Immune Responses}

Adaptive immune responses against tumors are generated in secondary lymphoid organs (SLOs), particularly in LN draining of pathological sites. They provide suitable microenvironments for the activation and expansion of antigen-specific lymphocytes. In these collaborative environments, lymphocytes move along stromal networks to scan the surfaces of antigen-presenting cells (APCs) for cognate antigens. The interactions between stromal and hematopoietic cells in SLOs are critical for the function of immune cells [34]. There are different stromal subtypes according to their surface marker: CD31 and podoplanin (PDPN, also known as gp38 and T1 $\alpha$ ) [35]. Fibroblastic reticular cells (FRCs, gp $38^{+} \mathrm{CD} 31^{-}$) in SLOs secrete chemokines CCL19 and CCL21, to attract T cells and DCs and orchestrate a complex network of collagens and extracellular matrix to facilitate the migration of these cells [36-38]. Simultaneously, FRCs are the main cellular source of IL-7 in the periphery, which is a survival signal to lymphocytes immigrating into SLOs [8]. The lymphatic vessel is enclosed with lymphatic endothelial cells (LECs, gp $38^{+} \mathrm{CD} 31^{+}$), which not only convey signaling in the lymph 
further upstream, but it also induces peripheral tolerance $[35,39,40]$. LECs are the prominent source of IL-7 in human fetal mesenteric LNs [9]. Our team recently found that IL-7 produced in the spleen of tumor-bearing mice was significantly decreased (data not published). Inadequate supply of IL-7 in SLOs might be insufficient to support the survival of activated $\mathrm{T}$ cells, thereby aggravating the immunosuppression of cancer.

\section{Application of IL-7 in Cancer Immunotherapy}

Cytokines have been applied in cancer immunotherapy for many years, of which IL-2 was approved by the U.S. Food and Drug Administration (FDA) for the treatment of patients with metastatic melanoma. But it required high-dose of IL-2 to achieve significant clinical response which resulted in dose-related fever, serious biochemical abnormalities in the liver and kidney, and capillary leak [41]. IL-2 stimulates proliferation of effector cells that kill cancer cells but it also plays an important role in the maintenance of regulatory $\mathrm{T}$ (Treg) in the periphery that suppresses the immune response [42]. IL-15 has a pivotal role in life and death of NK and memory $\mathrm{CD}^{+} \mathrm{T}$ cells [43]. But it will cause fever, rigors and blood pressure dropping [42]. It also induces the expression of the immunosuppressive receptor, programmed cell death protein 1 (PD-1) and increases the immunosuppressive cytokine IL-10 secreted by $\mathrm{CD} 8^{+} \mathrm{T}$ cells [44].

Investigators aim to utilize IL-7 to enhance the efficacy of tumor regression. A set of preclinical trials has proven that IL-7 can prolong the survival of tumor-bearing hosts in several tumor models. In murine mammary carcinoma, the administration of IL-7 and IL-15 after radiofrequency thermal ablation (RFA) resulted in a relapse-free survival and showed inhibition of metastatic nodules in their lungs [45]. Adoptive immunotherapy, wherein tumor-specific CTLs are activated and expanded in vitro with bryostatin and ionomycin, that were infused back into the body of the animals, has greater regression of established melanoma and 4T1 mammary carcinomas in vivo if the cells were cultured in IL-7 and IL-15 compared with IL-2 alone [46,47]. Interestingly, intratumoral injection with adenoviral IL-7 transduced DCs resulted in complete tumor regression in a murine lung cancer model [48]. IL-7 producing whole cell vaccine is also proved to evoke an effective anti-cancer immune response, probably mediated by $\mathrm{NK}_{1} 1^{+}$cells for subcutaneous prostate cancer challenge [49], while the GM-CSF producing vaccine is good at intraprostatic tumor challenge [50]. In the clinical trials reported in 2006, 2008 and 2010, patients with different kinds of cancers such as metastatic melanoma or sarcoma were injected subcutaneously with different doses of IL-7. Little toxicity was seen except for transient fevers and mild erythema. Circulating levels of both $\mathrm{CD} 4^{+}$and $\mathrm{CD} 8^{+} \mathrm{T}$ cells increased significantly and the number of Treg reduced. TCR repertoire diversity increased after IL-7 therapy. But the anti-tumor activity of IL-7 was not well evaluated [51-53].

\subsection{IL-7 for Immune Reconstitution in Cancer Patients}

Cancer patients often suffer from immunosuppression with low $\mathrm{T}$ cell counts [54]. This situation will deteriorate when the patients received chemotherapy as a side-effect of drugs via myelosuppression. IL-7 administration can enhance their immune reconstitution [5,6], mainly from the homeostatic expansion of peripheral $\mathrm{T}$ cell populations. IL-7 therapy not only increases both $\mathrm{T}$ cell counts [55] and the diversity of $\mathrm{T}$ cells recognizing different antigens [53], but it also promotes the homing of $\mathrm{T}$ cells to 
lymphoid tissues where antigen recognition occurs [56]. It has also been reported that IL-7 can increase thymopoiesis to fill-up the pool of naïve T cells [57]. RhIL-7 has been applied in a phase I study with a significant increase in peripheral $\mathrm{CD}^{+}$and $\mathrm{CD}^{+} \mathrm{T}$ lymphocytes in patients with refractory malignancy [51].

\subsection{IL-7 Enhances the Function of Effector Immune Cells}

The IL-7 treatment can improve the function of immune cells in vivo. As an adjuvant, IL-7 enhances long-term tumor antigen-specific CTLs responses in both quantity and quality after immunization with recombinant lentivector [58]. First, it can recruit multiple effector cells, such as CTLs, natural killer (NK) and NKT cells to infiltrate the tumor sites. The T helper type 17 (Th17) subset of $\mathrm{CD}^{+} \mathrm{T}$ cells is well known in promoting inflammation and pathology in animal models. In addition to CTLs, the number of infiltrated Th17 cells also increases with IL-7 adjuvant [59], which is potentially driven by the increased total number of $\mathrm{CD}^{+} \mathrm{T}$ cells. Next, it represses Casitas B-lineage lymphoma-b (Cbl-b), a negative regulator of $\mathrm{T}$ cell activation, to maintain $\mathrm{CD} 8^{+} \mathrm{T}$ cells survival [59]. These $\mathrm{CD}^{+} \mathrm{T}$ cells can continue to proliferate even under conditions where the antigen and other cytokines are limited. Simultaneously, increased CTLs infiltration produces more IFN- $\gamma$ in mouse melanoma, colon and breast cancer models [60-62] and upregulates granzyme B expression [59]. Memory $\mathrm{T}$ cells can persist long-term to patrol the entire organism for residual tumor cells. IL-7 can also improve the survival of IL-7- $\alpha^{+}$central memory populations and promote the production of IL-7R $\alpha^{+}$long-living memory stem $\mathrm{T}$ cells (TSCM), which can self-renew and demonstrates the plasticity to differentiate into effectors [63]. The antigen recognition relies on the host APC acting with TCR. The utility of the chimeric homeostatic cytokine, IL-7/IL-7R $\alpha-F c$, partly restored APC activities in lung cancer, with a stronger capacity to process and present antigens to activate $\mathrm{CD}^{+} \mathrm{T}$ cells [64].

\subsection{IL-7 Antagonizes the Immunosuppressive Network}

Several reports have shown that IL-7 is able to antagonize the immunosuppressive network [59]. This network consists of inhibitory cytokines and immunosuppressive cells, such as Treg and MDSC. It is well established that cancer-associated $\mathrm{CD}^{+} \mathrm{T}$ cells exhibit a phenotype known as exhaustion, with high PD-1 expression. IL-7 can diminish PD-1 expression on activated CD $8^{+} \mathrm{T}$ cells such that they are revitalized [59]. Some tumor cells can secrete TGF- $\beta$ that signals via the SMAD protein to inhibit the proliferation of $\mathrm{CD}^{+} \mathrm{T}$ cells. IL-7 can abrogate this inhibitory effect via an induction of the expression of SMAD ubiquitylation regulatory factor 2 (SMURF2) [59]. Treg accumulates in the tumor microenvironment and inhibits immune responses. Treg cells have low expression of CD127 and high level of CD132 on their surface. IL-7 can directly abrogate the Treg-mediated suppression of effector $\mathrm{T}$ cell proliferation [65] and decrease the population of Treg in spleen of lung cancer model [66]. Intralesional injection with IL-7 and IL-15 in RFA-treated animals can also reduce the proportion of MDSC present in the spleen in murine mammary carcinoma [45]. However, IL-7 has little effect on the proliferation of Treg and MDSC. Thus, the decreased proportion of Treg and MDSC may be the result of significant proliferation of naïve T cells with IL-7 therapy. 


\section{Potential Caveat of the Use of IL-7}

IL-7 signaling is well known to occur in either the initiation or maintenance of some lymphocyte-derived tumors, such as T-cell acute lymphoblastic leukemia [67,68]. IL-7 appears to be involved in autocrine circuitries to maintain the growth of lymphoma cells [69]. Lesional skin from cutaneous T-cell lymphomas patients can secrete more IL-7, which contributes with the proliferation of lymphoma cells [70]. Nevertheless, both IL-7 and its receptor are also found in some solid tumor samples. IL-7 mRNA is detected in colorectal, esophageal, renal, head and neck squamous cell carcinoma, as well as in Warthin's tumors of the parotid gland [71]. Prostatic epithelia constitutively produce IL-7 but decrease its production dramatically during the neoplastic glands formation [10]. But serum titers of IL-7 significantly increased in prostate cancer patients [72-74]. IL-7 levels were strongly associated with ovarian cancer and could be used in combination with CA-125 to distinguish between malignant and benign ovarian tumors [75]. In non-small-cell lung carcinoma patients' biopsies, IL-7 was highly expressed by bone invading cells [76]. IL-7R mRNA is expressed in the breast, lung, colon, renal and CNS cancer cell lines [77]. High expression of tumor IL-7R is associated with worse outcome in patients with stage I lung adenocarcinoma [78].

There is no data demonstrating the exact cell source of IL-7 detected in tumor sample. Was it obtained from tumor cells themselves or from stromal cells in the tumor tissue? Moreover, the source of increased IL-7 in serum was not defined to-date. It is unclear whether IL-7 may signal tumors themselves to accelerate the progression of cancer. There has not been good data to demonstrate that IL-7 receptor expressed on solid tumors is functional or that IL-7 contributes to tumor growth [79]. As a result, further research studies are needed to justify the function status of IL-7R expressed on tumor cells. Perhaps different tumor models will have a different reaction to IL-7 therapy. IL-7 is likely to work only in some types of cancer.

\section{Conclusions}

Modulation of the IL-7 axis is an ideal tool for repairing damaged immune systems in cancer patients, particularly those who received chemotherapy (Figure 1). IL-7 can promote immune reconstitution both from thymus-independent homeostatic expansion of peripheral $\mathrm{T}$ cells and thymopoiesis. It guides more CTLs and other immune effector cells infiltration with better survival and upregulated killing activities. IL-7 fights against the immunosuppressive network to improve immune function on cancer cells. Blockade of IL-7 and/or its receptor is feasible in lymphoid malignancies that are dependent upon IL-7 signaling. However, the function of IL-7 and its receptor expressed in some solid tumor remain to be clarified. The situation will deteriorate if the solid tumor expresses a functional IL-7R that promotes cancer progression. Whether IL-7R should be detected in tumor sample before IL-7 administration will require further research. 


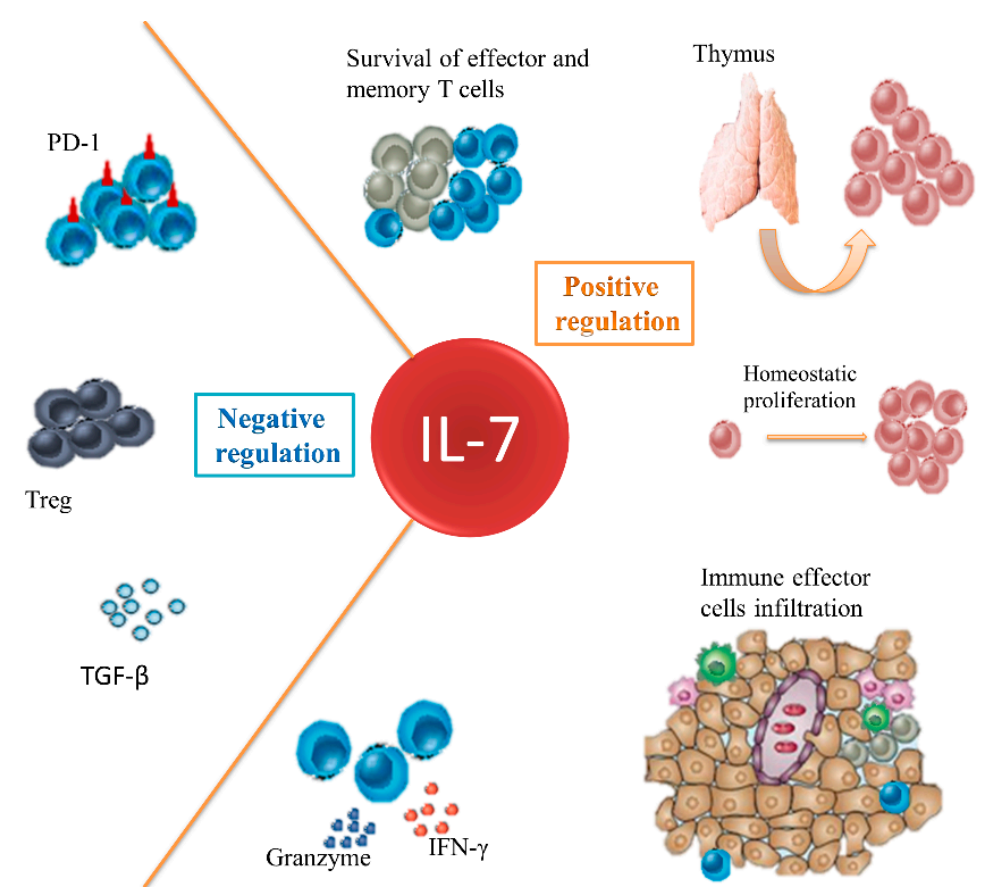

Figure 1. Effects of IL-7 in cancer immunotherapy. IL-7 can maintain the survival of CTLs and memory $\mathrm{T}$ cells. It promotes immune reconstitution both from the thymus-independent homeostatic expansion of peripheral $\mathrm{T}$ cells and thymopoiesis. It enhances the efficacy of tumor regression by enhancing effector cells infiltration, such as CTL, NK, NKT and Th17 with an upregulated killing capability. It also antagonizes the immunosuppressive network.

\section{Acknowledgments}

This work was supported by the National Nature Science Foundation of China (Grant Nos. 81070018, 81071772 and 81222031), by the outstanding Youth Scientist Foundation of Chongqing (No. CSTC, 2008BA5035) and by the National Key Basic Research Program of China (973 program, Grant Nos. 010CB529404 and 2012CB526603).

\section{Author Contributions}

Jianbao Gao: Literature research, writing the manuscript and create the figure; Lintao Zhao: Literature research and writing the manuscript; Yisong Y. Wan: writing revision; and Bo Zhu: Concept, writing and manuscript revision.

\section{Conflicts of Interest}

The authors declare no conflict of interest.

\section{References}

1. Puel, A.; Ziegler, S.F.; Buckley, R.H.; Leonard, W.J. Defective IL7R expression in $\mathrm{T}^{-} \mathrm{B}^{+} \mathrm{NK}^{+}$ severe combined immunodeficiency. Nat. Genet. 1998, 20, 394-397.

2. Surh, C.D.; Sprent, J. Homeostasis of naive and memory T cells. Immunity 2008, 29, 848-862. 
3. Kittipatarin, C.; Khaled, A.R. Interlinking interleukin-7. Cytokine 2007, 39, 75-83.

4. Hanahan, D.; Weinberg, R.A. Hallmarks of cancer: The next generation. Cell 2011, 144, 646-674.

5. ElKassar, N.; Gress, R.E. An overview of IL-7 biology and its use in immunotherapy. J. Immunotoxicol. 2010, 7, 1-7.

6. Lundstrom, W.; Fewkes, N.M.; Mackall, C.L. IL-7 in human health and disease. Semin. Immunol. 2012, 24, 218-224.

7. Mazzucchelli, R.I.; Warming, S.; Lawrence, S.M.; Ishii, M.; Abshari, M.; Washington, A.V.; Feigenbaum, L.; Warner, A.C.; Sims, D.J.; Li, W.Q.; et al. Visualization and identification of IL-7 producing cells in reporter mice. PLoS ONE 2009, 4, e7637.

8. Link, A.; Vogt, T.K.; Favre, S.; Britschgi, M.R.; Acha-Orbea, H.; Hinz, B.; Cyster, J.G.; Luther, S.A. Fibroblastic reticular cells in lymph nodes regulate the homeostasis of naive T cells. Nat. Immunol. 2007, 8, 1255-1265.

9. Onder, L.; Narang, P.; Scandella, E.; Chai, Q.; Iolyeva, M.; Hoorweg, K.; Halin, C.; Richie, E.; Kaye, P.; Westermann, J.; et al. IL-7-producing stromal cells are critical for lymph node remodeling. Blood 2012, 120, 4675-4683.

10. Di Carlo, E.; D’Antuono, T.; Pompa, P.; Giuliani, R.; Rosini, S.; Stuppia, L.; Musiani, P.; Sorrentino, C. The lack of epithelial interleukin-7 and BAFF/BLyS gene expression in prostate cancer as a possible mechanism of tumor escape from immunosurveillance. Clin. Cancer Res. 2009, 15, 2979-2987.

11. Guimond, M.; Veenstra, R.G.; Grindler, D.J.; Zhang, H.; Cui, Y.; Murphy, R.D.; Kim, S.Y.; $\mathrm{Na}, \mathrm{R}$; Hennighausen, L.; Kurtulus, S.; et al. Interleukin 7 signaling in dendritic cells regulates the homeostatic proliferation and niche size of CD4 ${ }^{+} \mathrm{T}$ cells. Nat. Immunol. 2009, 10, 149-157.

12. Golden-Mason, L.; Kelly, A.M.; Traynor, O.; McEntee, G.; Kelly, J.; Hegarty, J.E.; O’Farrelly, C. Expression of interleukin 7 (IL-7) mRNA and protein in the normal adult human liver: Implications for extrathymic T cell development. Cytokine 2001, 14, 143-151.

13. Sawa, Y.; Arima, Y.; Ogura, H.; Kitabayashi, C.; Jiang, J.J.; Fukushima, T.; Kamimura, D.; Hirano, T.; Murakami, M. Hepatic interleukin-7 expression regulates T cell responses. Immunity 2009, 30, 447-457.

14. Jiang, Q.; Li, W.Q.; Aiello, F.B.; Mazzucchelli, R.; Asefa, B.; Khaled, A.R.; Durum, S.K. Cell biology of IL-7, a key lymphotrophin. Cytokine Growth Factor Rev. 2005, 16, 513-533.

15. Kang, J.; Coles, M. IL-7: The global builder of the innate lymphoid network and beyond, one niche at a time. Semin. Immunol. 2012, 24, 190-197.

16. Kerdiles, Y.M.; Beisner, D.R.; Tinoco, R.; Dejean, A.S.; Castrillon, D.H.; DePinho, R.A.; Hedrick, S.M. Foxo1 links homing and survival of naive T cells by regulating 1-selectin, CCR7 and interleukin 7 receptor. Nat. Immunol. 2009, 10, 176-184.

17. Ouyang, W.; Beckett, O.; Flavell, R.A.; Li, M.O. An essential role of the forkhead-box transcription factor foxol in control of $\mathrm{T}$ cell homeostasis and tolerance. Immunity 2009, 30, $358-371$.

18. Xue, H.H.; Bollenbacher, J.; Rovella, V.; Tripuraneni, R.; Du, Y.B.; Liu, C.Y.; Williams, A.; McCoy, J.P.; Leonard, W.J. GA binding protein regulates interleukin 7 receptor $\alpha$-chain gene expression in T cells. Nat. Immunol. 2004, 5, 1036-1044. 
19. Park, J.H.; Yu, Q.; Erman, B.; Appelbaum, J.S.; Montoya-Durango, D.; Grimes, H.L.; Singer, A. Suppression of IL 7R $\alpha$ transcription by IL-7 and other prosurvival cytokines: A novel mechanism for maximizing IL-7-dependent T cell survival. Immunity 2004, 21, 289-302.

20. Ouyang, W.; Oh, S.A.; Ma, Q.; Bivona, M.R.; Zhu, J.; Li, M.O. TGF- $\beta$ cytokine signaling promotes $\mathrm{CD}^{+} \mathrm{t}$ cell development and low-affinity $\mathrm{CD}^{+} \mathrm{T}$ cell homeostasis by regulation of interleukin-7 receptor $\alpha$ expression. Immunity 2013, 39, 335-346.

21. Lundstrom, W.; Highfill, S.; Walsh, S.T.; Beq, S.; Morse, E.; Kockum, I.; Alfredsson, L.; Olsson, T.; Hillert, J.; Mackall, C.L. Soluble IL7R $\alpha$ potentiates IL-7 bioactivity and promotes autoimmunity. Proc. Natl. Acad. Sci. USA 2013, 110, E1761-E1770.

22. Swainson, L.; Kinet, S.; Mongellaz, C.; Sourisseau, M.; Henriques, T.; Taylor, N. IL-7-induced proliferation of recent thymic emigrants requires activation of the PI3K pathway. Blood 2007, 109, 1034-1042.

23. Fujita, N.; Sato, S.; Katayama, K.; Tsuruo, T. Akt-dependent phosphorylation of p27 ${ }^{\text {kip } 1}$ promotes binding to 14-3-3 and cytoplasmic localization. J. Biol. Chem. 2002, 277, 28706-28713.

24. Barata, J.T.; Silva, A.; Brandao, J.G.; Nadler, L.M.; Cardoso, A.A.; Boussiotis, V.A. Activation of $\mathrm{PI} 3 \mathrm{~K}$ is indispensable for interleukin 7-mediated viability, proliferation, glucose use, and growth of T cell acute lymphoblastic leukemia cells. J. Exp. Med. 2004, 200, 659-669.

25. Patra, A.K.; Avots, A.; Zahedi, R.P.; Schuler, T.; Sickmann, A.; Bommhardt, U.; Serfling, E. An alternative NFAT-activation pathway mediated by IL-7 is critical for early thymocyte development. Nat. Immunol. 2013, 14, 127-135.

26. Mazzucchelli, R.; Durum, S.K. Interleukin-7 receptor expression: Intelligent design. Nat. Rev. Immunol. 2007, 7, 144-154.

27. Schlissel, M.S.; Durum, S.D.; Muegge, K. The interleukin 7 receptor is required for $\mathrm{t}$ cell receptor gamma locus accessibility to the V(D)J recombinase. J. Exp. Med. 2000, 191, 1045-1050.

28. Bolotin, E.; Annett, G.; Parkman, R.; Weinberg, K. Serum levels of IL-7 in bone marrow transplant recipients: Relationship to clinical characteristics and lymphocyte count. Bone Marrow Transplant. 1999, 23, 783-788.

29. Jameson, S.C. Maintaining the norm: T-cell homeostasis. Nat. Rev. Immunol. 2002, 2, 547-556.

30. Bream, J.H.; Hodge, D.L.; Gonsky, R.; Spolski, R.; Leonard, W.J.; Krebs, S.; Targan, S.; Morinobu, A.; O'Shea, J.J.; Young, H.A. A distal region in the interferon- $\gamma$ gene is a site of epigenetic remodeling and transcriptional regulation by interleukin-2. J. Biol. Chem. 2004, 279, $41249-41257$.

31. Kimura, M.Y.; Pobezinsky, L.A.; Guinter, T.I.; Thomas, J.; Adams, A.; Park, J.H.; Tai, X.; Singer, A. IL-7 signaling must be intermittent, not continuous, during $\mathrm{CD} 8^{+} \mathrm{T}$ cell homeostasis to promote cell survival instead of cell death. Nat. Immunol. 2013, 14, 143-151.

32. Noguchi, M.; Sarin, A.; Aman, M.J.; Nakajima, H.; Shores, E.W.; Henkart, P.A.; Leonard, W.J. Functional cleavage of the common cytokine receptor $\gamma$ chain $(\gamma \mathrm{c})$ by calpain. Proc. Natl. Acad. Sci. USA 1997, 94, 11534-11539.

33. Katz, G.; Pobezinsky, L.A.; Jeurling, S.; Shinzawa, M.; van Laethem, F.; Singer, A. T cell receptor stimulation impairs IL-7 receptor signaling by inducing expression of the microrna miR-17 to target janus kinase 1. Sci. Signal. 2014, 7, doi:10.1126/scisignal.2005221. 
34. Malhotra, D.; Fletcher, A.L.; Turley, S.J. Stromal and hematopoietic cells in secondary lymphoid organs: Partners in immunity. Immunol. Rev. 2013, 251, 160-176.

35. Turley, S.J.; Fletcher, A.L.; Elpek, K.G. The stromal and haematopoietic antigen-presenting cells that reside in secondary lymphoid organs. Nat. Rev. Immunol. 2010, 10, 813-825.

36. Bajenoff, M.; Egen, J.G.; Koo, L.Y.; Laugier, J.P.; Brau, F.; Glaichenhaus, N.; Germain, R.N. Stromal cell networks regulate lymphocyte entry, migration, and territoriality in lymph nodes. Immunity 2006, 25, 989-1001.

37. Zhao, L.; Liu, L.; Gao, J.; Yang, Y.; Hu, C.; Guo, B.; Zhu, B. T lymphocytes maintain structure and function of fibroblastic reticular cells via lymphotoxin (LT)-B. BMC Immunol. 2014, 15, doi:10.1186/s12865-014-0033-4.

38. Zhao, L.; Chen, J.; Liu, L.; Gao, J.; Guo, B.; Zhu, B. Essential role of TNF- $\alpha$ in development of spleen fibroblastic reticular cells. Cell. Immunol. 2015, 293, 130-136.

39. Anne, L.; Fletcher, D.M.; Shannon, J.T. Lymph node stroma broaden the peripheral tolerance paradigm. Trends Immunol. 2011, 32, 6.

40. Lund, A.W.; Duraes, F.V.; Hirosue, S.; Raghavan, V.R.; Nembrini, C.; Thomas, S.N.; Issa, A.; Hugues, S.; Swartz, M.A. VEGF-c promotes immune tolerance in B16 melanomas and cross-presentation of tumor antigen by lymph node lymphatics. Cell Rep. 2012, 1, 191-199.

41. Rosenberg, S.A. IL-2: The first effective immunotherapy for human cancer. J. Immunol. 2014, 192, 5451-5458.

42. Waldmann, T.A. The shared and contrasting roles of IL2 and IL15 in the life and death of normal and neoplastic lymphocytes: Implications for cancer therapy. Cancer Immunol. Res. 2015, 3, 219-227.

43. Zarogoulidis, P.; Lampaki, S.; Yarmus, L.; Kioumis, I.; Pitsiou, G.; Katsikogiannis, N.; Hohenforst-Schmidt, W.; Li, Q.; Huang, H.; Sakkas, A.; et al. Interleukin-7 and interleukin-15 for cancer. J. Cancer 2014, 5, 765-773.

44. Steel, J.C.; Waldmann, T.A.; Morris, J.C. Interleukin-15 biology and its therapeutic implications in cancer. Trends Pharmacol. Sci. 2012, 33, 35-41.

45. Habibi, M.; Kmieciak, M.; Graham, L.; Morales, J.K.; Bear, H.D.; Manjili, M.H. Radiofrequency thermal ablation of breast tumors combined with intralesional administration of IL-7 and IL-15 augments anti-tumor immune responses and inhibits tumor development and metastasis. Breast Cancer Res. Treat. 2009, 114, 423-431.

46. Le, H.K.; Graham, L.; Miller, C.H.; Kmieciak, M.; Manjili, M.H.; Bear, H.D. Incubation of antigen-sensitized $\mathrm{T}$ lymphocytes activated with bryostatin $1+$ ionomycin in IL-7 + IL-15 increases yield of cells capable of inducing regression of melanoma metastases compared to culture in IL-2. Cancer Immunol. Immunother. 2009, 58, 1565-1576.

47. Cha, E.; Graham, L.; Manjili, M.H.; Bear, H.D. IL-7 + IL-15 are superior to IL-2 for the ex vivo expansion of 4T1 mammary carcinoma-specific $\mathrm{T}$ cells with greater efficacy against tumors in vivo. Breast Cancer Res. Treat. 2010, 122, 359-369.

48. Miller, P.W.; Sharma, S.; Stolina, M.; Butterfield, L.H.; Luo, J.; Lin, Y.; Dohadwala, M.; Batra, R.K.; Wu, L.; Economou, J.S.; et al. Intratumoral administration of adenoviral interleukin 7 gene-modified dendritic cells augments specific antitumor immunity and achieves tumor eradication. Hum. Gene Ther. 2000, 11, 53-65. 
49. Schroten, C.; Scheffer, R.; Boon, L.; de Ridder, C.M.; Bangma, C.H.; Kraaij, R. Tumor protection by IL-7 secreting whole cell vaccine is merely mediated by NK1.1-positive cells. J. Immunother. 2012, 35, 125-130.

50. Schroten-Loef, C.; de Ridder, C.M.; Reneman, S.; Crezee, M.; Dalgleish, A.; Todryk, S.M.; Bangma, C.H.; Kraaij, R. A prostate cancer vaccine comprising whole cells secreting IL-7, effective against subcutaneous challenge, requires local GM-CSF for intra-prostatic efficacy. Cancer Immunol. Immunother. 2009, 58, 373-381.

51. Sportes, C.; Babb, R.R.; Krumlauf, M.C.; Hakim, F.T.; Steinberg, S.M.; Chow, C.K.; Brown, M.R.; Fleisher, T.A.; Noel, P.; Maric, I.; et al. Phase I study of recombinant human interleukin-7 administration in subjects with refractory malignancy. Clin. Cancer Res. 2010, 16, $727-735$.

52. Rosenberg, S.A.; Sportes, C.; Ahmadzadeh, M.; Fry, T.J.; Ngo, L.T.; Schwarz, S.L.; Stetler-Stevenson, M.; Morton, K.E.; Mavroukakis, S.A.; Morre, M.; et al. IL-7 administration to humans leads to expansion of $\mathrm{CD}^{+}$and $\mathrm{CD}^{+}$cells but a relative decrease of $\mathrm{CD}^{+} \mathrm{T}$-regulatory cells. J. Immunother. 2006, 29, 313-319.

53. Sportes, C.; Hakim, F.T.; Memon, S.A.; Zhang, H.; Chua, K.S.; Brown, M.R.; Fleisher, T.A.; Krumlauf, M.C.; Babb, R.R.; Chow, C.K.; et al. Administration of rhIL-7 in humans increases in vivo TCR repertoire diversity by preferential expansion of naive T cell subsets. J. Exp. Med. 2008, 205, 1701-1714.

54. Ray-Coquard, I.; Cropet, C.; van Glabbeke, M.; Sebban, C.; le Cesne, A.; Judson, I.; Tredan, O.; Verweij, J.; Biron, P.; Labidi, I.; et al. Lymphopenia as a prognostic factor for overall survival in advanced carcinomas, sarcomas, and lymphomas. Cancer Res. 2009, 69, 5383-5391.

55. Lu, H.; Zhao, Z.; Kalina, T.; Gillespy, T., III; Liggitt, D.; Andrews, R.G.; Maloney, D.G.; Kiem, H.P.; Storek, J. Interleukin-7 improves reconstitution of antiviral CD4 T cells. Clin. Immunol. 2005, 114, 30-41.

56. Beq, S.; Rozlan, S.; Gautier, D.; Parker, R.; Mersseman, V.; Schilte, C.; Assouline, B.; Rance, I.; Lavedan, P.; Morre, M.; et al. Injection of glycosylated recombinant simian IL-7 provokes rapid and massive T-cell homing in rhesus macaques. Blood 2009, 114, 816-825.

57. Okamoto, Y.; Douek, D.C.; McFarland, R.D.; Koup, R.A. Effects of exogenous interleukin-7 on human thymus function. Blood 2002, 99, 2851-2858.

58. Colombetti, S.; Levy, F.; Chapatte, L. IL-7 adjuvant treatment enhances long-term tumor-antigenspecific $\mathrm{CD}^{+} \mathrm{T}$-cell responses after immunization with recombinant lentivector. Blood 2009, 113, 6629-6637.

59. Pellegrini, M.; Calzascia, T.; Elford, A.R.; Shahinian, A.; Lin, A.E.; Dissanayake, D.; Dhanji, S.; Nguyen, L.T.; Gronski, M.A.; Morre, M.; et al. Adjuvant IL-7 antagonizes multiple cellular and molecular inhibitory networks to enhance immunotherapies. Nat. Med. 2009, 15, 528-536.

60. Zhao, L.; Mei, Y.; Sun, Q.; Guo, L.; Wu, Y.; Yu, X.; Hu, B.; Liu, X.; Liu, H. Autologous tumor vaccine modified with recombinant new castle disease virus expressing IL-7 promotes antitumor immune response. J. Immunol. 2014, 193, 735-745.

61. Yuan, C.H.; Yang, X.Q.; Zhu, C.L.; Liu, S.P.; Wang, B.C.; Wang, F.B. Interleukin-7 enhances the in vivo anti-tumor activity of tumor-reactive $\mathrm{CD}^{+} \mathrm{T}$ cells with induction of IFN- $\gamma$ in a murine breast cancer model. Asian Pac. J. Cancer Prev. 2014, 15, 265-271. 
62. Lai, L.; Jin, J.; Goldschneider, I. In vivo antitumor activity of a recombinant IL-7/HGF $\beta$ hybrid cytokine in mice. Cancer Res. 2011, 71, 61-67.

63. Cieri, N.; Camisa, B.; Cocchiarella, F.; Forcato, M.; Oliveira, G.; Provasi, E.; Bondanza, A.; Bordignon, C.; Peccatori, J.; Ciceri, F.; et al. IL-7 and IL-15 instruct the generation of human memory stem T cells from naive precursors. Blood 2013, 121, 573-584.

64. Andersson, A.; Srivastava, M.K.; Harris-White, M.; Huang, M.; Zhu, L.; Elashoff, D.; Strieter, R.M.; Dubinett, S.M.; Sharma, S. Role of CXCR3 ligands in IL-7/IL-7R $\alpha$-FC-mediated antitumor activity in lung cancer. Clin. Cancer Res. 2011, 17, 3660-3672.

65. Heninger, A.K.; Theil, A.; Wilhelm, C.; Petzold, C.; Huebel, N.; Kretschmer, K.; Bonifacio, E.; Monti, P. IL-7 abrogates suppressive activity of human $\mathrm{CD} 4{ }^{+} \mathrm{CD} 25^{+} \mathrm{Foxp} 3^{+}$regulatory $\mathrm{T}$ cells and allows expansion of alloreactive and autoreactive t cells. J. Immunol. 2012, 189, 5649-5658.

66. Andersson, A.; Yang, S.C.; Huang, M.; Zhu, L.; Kar, U.K.; Batra, R.K.; Elashoff, D.; Strieter, R.M.; Dubinett, S.M.; Sharma, S. IL-7 promotes CXCR3 ligand-dependent T cell antitumor reactivity in lung cancer. J. Immunol. 2009, 182, 6951-6958.

67. Silva, A.; Laranjeira, A.B.; Martins, L.R.; Cardoso, B.A.; Demengeot, J.; Yunes, J.A.; Seddon, B.; Barata, J.T. IL-7 contributes to the progression of human T-cell acute lymphoblastic leukemias. Cancer Res. 2011, 71, 4780-4789.

68. Barata, J.T.; Cardoso, A.A.; Boussiotis, V.A. Interleukin-7 in T-cell acute lymphoblastic leukemia: An extrinsic factor supporting leukemogenesis? Leukemia Lymphoma 2005, 46, 483-495.

69. Cattaruzza, L.; Gloghini, A.; Olivo, K.; di Francia, R.; Lorenzon, D.; de Filippi, R.; Carbone, A.; Colombatti, A.; Pinto, A.; Aldinucci, D. Functional coexpression of interleukin (IL)-7 and its receptor (IL-7R) on hodgkin and reed-sternberg cells: Involvement of IL-7 in tumor cell growth and microenvironmental interactions of Hodgkin's lymphoma. Int. J. Cancer 2009, 125, 1092-1101.

70. Yamanaka, K.; Clark, R.; Rich, B.; Dowgiert, R.; Hirahara, K.; Hurwitz, D.; Shibata, M.; Mirchandani, N.; Jones, D.A.; Goddard, D.S.; et al. Skin-derived interleukin-7 contributes to the proliferation of lymphocytes in cutaneous T-cell lymphoma. Blood 2006, 107, 2440-2445.

71. Al-Rawi, M.A.; Mansel, R.E.; Jiang, W.G. Interleukin-7 (IL-7) and IL-7 receptor (IL-7R) signalling complex in human solid tumours. Histol. Histopathol. 2003, 18, 911-923.

72. Roato, I.; D’Amelio, P.; Gorassini, E.; Grimaldi, A.; Bonello, L.; Fiori, C.; Delsedime, L.; Tizzani, A.; Libero, A.D.; Isaia, G.; et al. Osteoclasts are active in bone forming metastases of prostate cancer patients. PLOS ONE 2008, 3, e3627.

73. Mengus, C.; le Magnen, C.; Trella, E.; Yousef, K.; Bubendorf, L.; Provenzano, M.; Bachmann, A.; Heberer, M.; Spagnoli, G.C.; Wyler, S. Elevated levels of circulating IL-7 and IL-15 in patients with early stage prostate cancer. J. Transl. Med. 2011, 9, doi:10.1186/14795876-9-162.

74. Schroten, C.; Dits, N.F.; Steyerberg, E.W.; Kranse, R.; van Leenders, A.G.; Bangma, C.H.; Kraaij, R. The additional value of TGF $\beta 1$ and IL-7 to predict the course of prostate cancer progression. Cancer Immunol. Immunother. 2012, 61, 905-910. 
75. Lambeck, A.J.; Crijns, A.P.; Leffers, N.; Sluiter, W.J.; ten Hoor, K.A.; Braid, M.; van der Zee, A.G.; Daemen, T.; Nijman, H.W.; Kast, W.M. Serum cytokine profiling as a diagnostic and prognostic tool in ovarian cancer: A potential role for interleukin 7. Clin. Cancer Res. 2007, 13, 2385-2391.

76. Roato, I.; Caldo, D.; Godio, L.; D’Amico, L.; Giannoni, P.; Morello, E.; Quarto, R.; Molfetta, L.; Buracco, P.; Mussa, A.; et al. Bone invading NSCLC cells produce IL-7: Mice model and human histologic data. BMC Cancer 2010, 10, doi:10.1186/1471-2407-10-12.

77. Cosenza, L.; Gorgun, G.; Urbano, A.; Foss, F. Interleukin-7 receptor expression and activation in nonhaematopoietic neoplastic cell lines. Cell Signal. 2002, 14, 317-325.

78. Suzuki, K.; Kadota, K.; Sima, C.S.; Nitadori, J.; Rusch, V.W.; Travis, W.D.; Sadelain, M.; Adusumilli, P.S. Clinical impact of immune microenvironment in stage I lung adenocarcinoma: Tumor interleukin-12 receptor $\beta 2$ (IL-12R $\beta 2$ ), IL-7R, and stromal Foxp3/CD3 ratio are independent predictors of recurrence. J. Clin. Oncol. 2013, 31, 490-498.

79. Capitini, C.M.; Chisti, A.A.; Mackall, C.L. Modulating t-cell homeostasis with IL-7: Preclinical and clinical studies. J. Intern. Med. 2009, 266, 141-153.

(C) 2015 by the authors; licensee MDPI, Basel, Switzerland. This article is an open access article distributed under the terms and conditions of the Creative Commons Attribution license (http://creativecommons.org/licenses/by/4.0/). 